\title{
Production of Pure Granules of Sba-15 Mesoporous Silica
}

\author{
Gabriela Oliveira de Magalhães $^{b *}$, Jéssica de Oliveira Notório Ribeiro ${ }^{b}$, Daniela Cordeiro Leite
}

\author{
Vasconcelos $^{a}$, Wander Luiz, Vasconcelos ${ }^{a}$ \\ ${ }^{a}$ Departamento de Engenharia Metalúrgica e de Materiais, Universidade Federal de Minas Gerais - \\ UFMG, CEP 31270-901, Belo Horizonte, MG, Brasil \\ ${ }^{b}$ Departamento de Engenharia Química, Universidade Federal de Minas Gerais - UFMG, CEP 31270 - \\ 901, Belo Horizonte, MG, Brasil
}

Received: February 25, 2018; Revised: July 24, 2018; Accepted: August 05, 2018

\begin{abstract}
Mesoporous silica materials have been widely investigated for their great potential as competitive adsorbents and catalysts in different areas, due to their ordered and uniform porous structures and high surface area. In order to increase the availability of these materials, the need to granulate them becomes vital for an efficient performance in industrial units. This study reports the production and characterization of clay-free granules of SBA-15 mesoporous silica, by applying the extrusion technique. The suggested methodology uses only methocel as the organic binder, which is removed after calcination. The granulation process was successfully achieved, producing pure granules of SBA15 mesoporous silica, in size of millimeters, with $8.3 \mathrm{MPa}$ of compacting pressure (by axial crushing test). The surface area and pore volume of SBA-15 mesoporous silica granules (calcined at $800{ }^{\circ} \mathrm{C}$ ) were around $392 \mathrm{~m}^{2} / \mathrm{g}$ and $0.53 \mathrm{~cm}^{3} / \mathrm{g}$, respectively.
\end{abstract}

Keywords: mesoporous materials, $S B A-15$, extrusion, clay-free granules.

\section{Introduction}

The disclosure of mesoporous materials has gained world attention in different field applications, namely adsorption and catalysis, due to their exceptional intrinsic features; e.g. highly ordered mesopore structure, high surface area, narrow pore size distribution, and thermal stability ${ }^{1-3}$. In addition, the popularity of mesoporous silicas' properties extended to the mesopore range the concept of molecular sieving, which was related before to zeolites ${ }^{4}$, in which the presence of micropores limits their catalytic performance in some applications. Therefore, a promising competitor to commercial zeolites and a significant family of mesoporous silica is known as the SBA-15 mesoporous silica, which is characterized by cylindrical and uniform pores, ordered in an hexagonal structure, with pore diameter varying from 4.6 to $30 \mathrm{~nm}^{5}$. Furthermore, the thickness of their amorphous framework wall (from 3.1 to $6.4 \mathrm{~nm})^{6}$ is responsible for enhancing the mechanical and chemical resistance properties of the SBA-15 mesoporous silica. Moreover, the tunable pore diameters favor the functionalization of further organic groups, e.g. amines and amides, which enhance and optimize SBA's adsorption and catalytic activity?

SBA-15 is usually synthesized by a cooperative selfassembly mechanism in an acidic media, using a triblock copolymer surfactant as a template, namely Pluronic P123 $\left(\mathrm{EO}_{20} \mathrm{PO}_{70} \mathrm{EO}_{20}\right)$, and a silicon source, often tetraethyl orthosilicate (TEOS, $\left.\mathrm{Si}\left(\mathrm{OC}_{2} \mathrm{H}_{5}\right)_{4}\right)$ or tetramethyl orthosilicate (TMOS, $\mathrm{Si}\left(\mathrm{OCH}_{3}\right)_{4}{ }^{8}$. The solution is mixed for $24 \mathrm{~h}$ at $40^{\circ} \mathrm{C}$

*e-mail: gabriela.o.magalhaes@gmail.com and then heated up to $100^{\circ} \mathrm{C}$ for $48 \mathrm{~h}$ in an autoclave, when the material reaches a sufficient degree of condensation. Therefore, the template is no longer needed and it can be removed by calcination, resulting in a porous structure 9 . Finally, the solid products are filtered, washed with water, dried at $100^{\circ} \mathrm{C}$ and calcined at $550{ }^{\circ} \mathrm{C}$ to remove the surfactant (template), obtaining highly ordered mesoporous materials $\mathrm{s}^{10,11}$, as illustrated in Figure 1

Nevertheless, in order to enhance their final properties and applications, one should have these mesoporous materials granulated. Among different granulation processes, the extrusion method has shown successful results shaping mesoporous silica into extrudated bodies ${ }^{12}$. Therefore, the preparation of extrudates is normally done by adding inorganic binders, such as bentonite, to increase the mechanical strength of the extrudates. Additionally, organic binders, such as methycellulose and hydroxyethylcellulose, plasticisers and surfactants can also be added to the formulation to help achieve a homogeneous and plastic wet mass to be extruded. However, in these common granulation procedures, the presence of the inorganic binders into the composition of the final granules might occlude a significant volume of pores of the mesoporous materials, decreasing the adsorption performance.

Moreover, mechanical strength is an important characteristic regarding the final extrudates, because it is responsible for conserving the integrity of the final body, the pore volume and the surface area, as well ensuring the reliable performance of the granules as adsorbents and desiccants.

In this work, powder of SBA-15 was synthesized and shaped into extrudates by extrusion process, using only methocel as organic binder to enhance the viscosity of the 


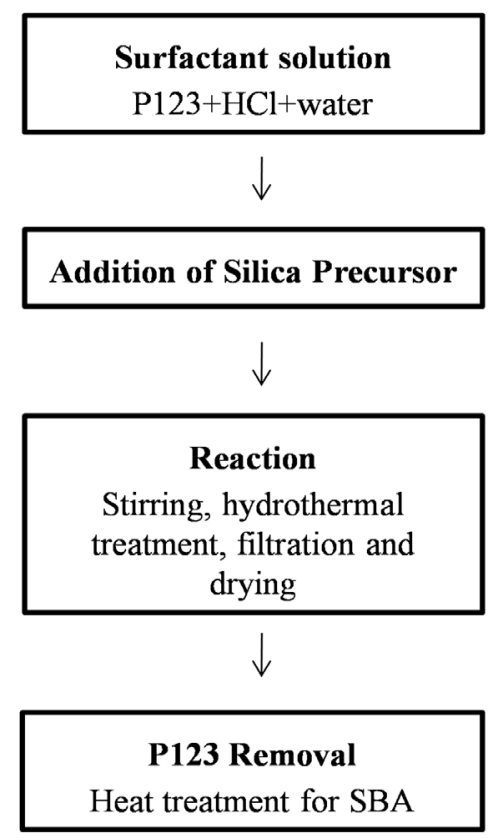

Figure 1. Schematic diagram for SBA-15 powder synthesis.

green body paste during extrusion, and also as a macropore builder, due to its removal after calcination process, producing clay-free granules of mesoporous silica. Another suggested improvement in the methodology regards the elimination of the calcination step during the synthesis SBA-15 mesoporous silica. The extrudates of SBA-15 are prepared with the presence of surfactant (template) and this template is removed together with the organic binder in the last calcination step of the extrusion process.

\section{Experimental}

\subsection{Materials}

For the synthesis of SBA-15 mesoporous materials, the materials used were the triblock copolymer surfactant Pluronic P123 - $\left(\mathrm{EO}_{20} \mathrm{PO}_{70} \mathrm{EO}_{20}\right.$, Sigma-Aldrich) and the tetraethylorthosilicate (TEOS - $\mathrm{Si}\left(\mathrm{OC}_{2} \mathrm{H}_{5}\right)_{4}$, Sigma-Aldrich, $98 \%$ ), used as structure directing agent (template) and a silicon source, respectively, and hydrochloric acid $(\mathrm{HCl}$ / Sigma-Aldrich / 37\%). The methylcellulose (Methocel A4M, Sigma-Aldrich) was used as organic binder in the extrusion process.

\subsection{Preparation of powder of SBA-15 mesoporous silica}

SBA-15 mesoporous silica powder was prepared by sol-gel route. Initially, P123 was completely dissolved in a solution of deionized water and $\mathrm{HCl}$, under vigorous stirring. Thereafter, TEOS was added into it and the stirring continued for $24 \mathrm{~h}$ at $40^{\circ} \mathrm{C}$. The powder product was filtered and washed with deionized water and then dried at $60{ }^{\circ} \mathrm{C}$ for at least $24 \mathrm{~h}$. The molar ratio used was 1 TEOS: $6 \mathrm{HCl}$ : $177 \mathrm{H}_{2} \mathrm{O}: 0.017 \mathrm{P} 123$.

\subsection{Preparation of SBA-15 mesoporous silica extrudates}

The SBA-15 extrudates were prepared by extrusion procedure $^{13}$, involving six main steps: powder mixing, paste preparation, extrusion, cutting, drying and calcination, as illustrated in Figure 2.

The final cylindrical extrudates were obtained by combining the dry components (un-calcined SBA-15 powder +20 wt. $\%$ of methocel $\mathrm{A} 4 \mathrm{M}$ ) and then by adding a minimum amount of deionized water into the dry mixture $(4 \mathrm{~mL}$ of water / $1 \mathrm{~g}$ of un-calcined SBA-15) until a uniform and consistent paste was formed. During this paste preparation stage, it was required an intensive mixing of water-solids to ensure homogeneity and consistency, in order to avoid further phase migration ${ }^{14}$. The wet paste was then transferred into an adapted metal screw extruder, with $3.8 \mathrm{~mm}$ diameter circular cross section die. Furthermore, the extrusion was achieved by constantly moving the screw manually, to obtain smooth extrudates, as illustrated in Figure 3. SBA-15 green body extrudates were cut in $4 \mathrm{~mm}$ length, and then they were dried at $60^{\circ} \mathrm{C}$ overnight. Finally, the SBA-15 cylindrical extrudates were calcined,

Un-calcinated SBA-15 powder

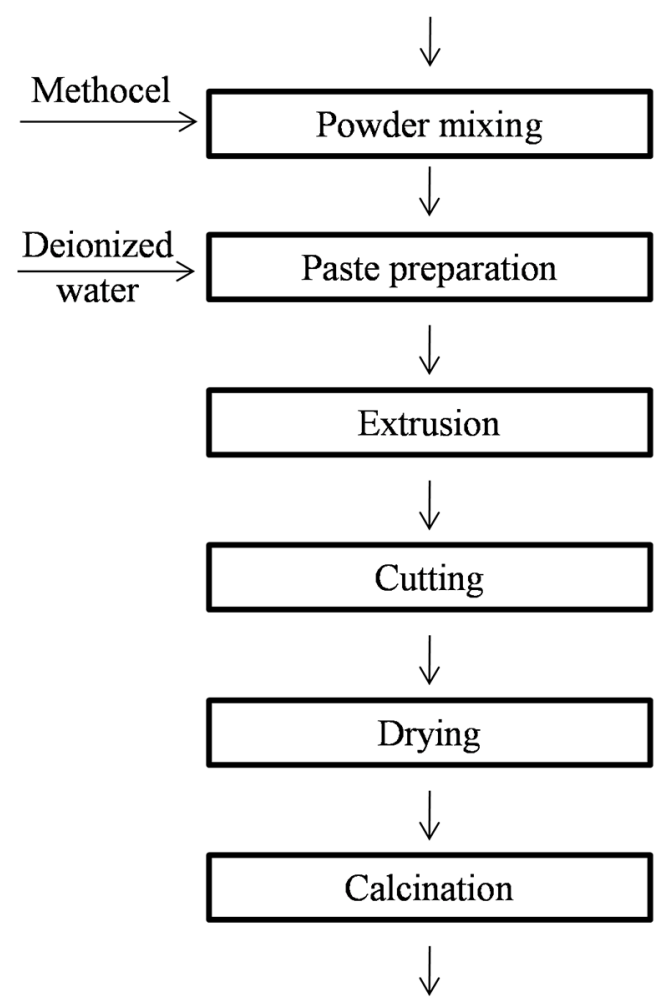

Final Cylindrical extrudates of SBA-15

Figure 2. Steps involved in the preparation of SBA-15 extrudates. 
at a rate of $1{ }^{\circ} \mathrm{C} / \mathrm{min}$ from room temperature to $800{ }^{\circ} \mathrm{C}$ for $1 \mathrm{~h}$, to remove the methocel and the surfactant (template). The photographs of the final clay-free SBA-15 extrudates obtained in this work are shown in Figure 4, with average diameter and length of $3 \mathrm{~mm}$ and $3.5 \mathrm{~mm}$, respectively.

\subsection{Characterization}

Nitrogen adsorption and desorption isotherms were carried out in a Micromeritics ASAP 2020 apparatus (at liquid nitrogen temperature of $-196^{\circ} \mathrm{C}$ ), using samples previously outgassed at $250^{\circ} \mathrm{C}$ for $24 \mathrm{~h}$ under vacuum. In addition, the specific surface area and pore size distribution were determined using the BET (Brunnauer-Emmett-Teller) and NLDFT (non-local density functional theory) methods, respectively.

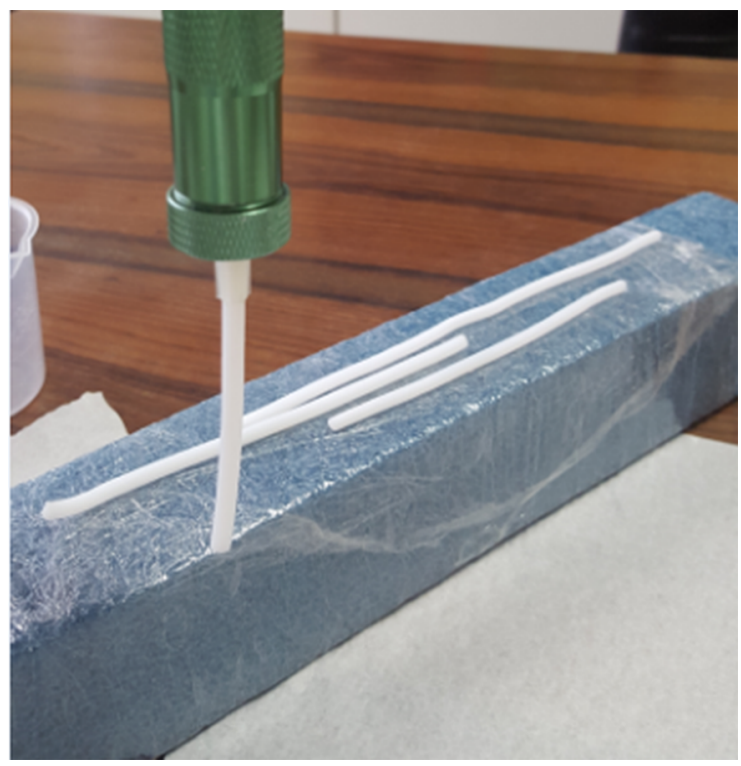

Figure 3. SBA-15 green body extrudates prepared with 20 wt. \% of methocel A4M.

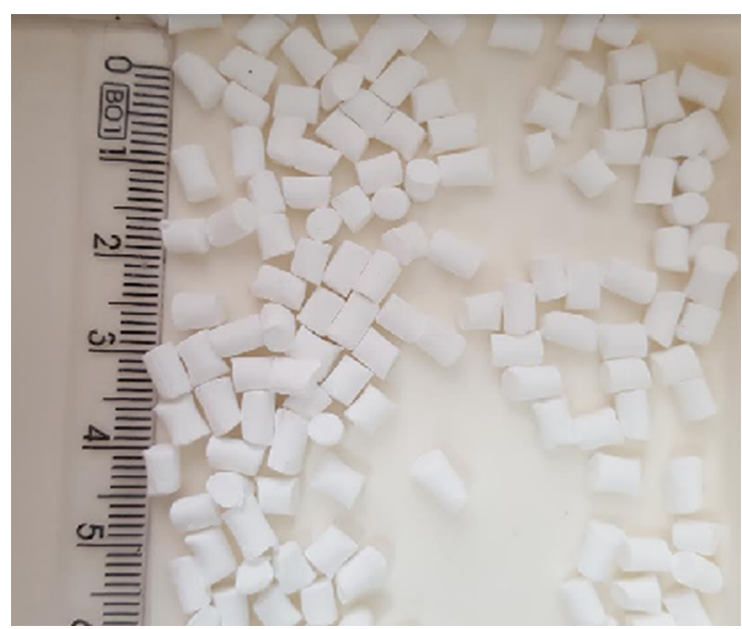

Figure 4. Final SBA-15 extrudates calcined at $800^{\circ} \mathrm{C}$.
The absence of methocel in the final extrusion compositions, after calcination process, was investigated by Fourier Transform Infrared Spectroscopy (FTIR) and by thermogravimetry analysis. The FTIR samples were prepared as pellets with $\mathrm{KBr}$ and examined in a Perkin-Elmer Frontier spectrometer, and the spectra were taken from 4000 to $300 \mathrm{~cm}^{-1}$, with a resolution of $2 \mathrm{~cm}^{-1}$ and 64 scans. The TG and DTG analysis were carried out in a Perkin-Elmer STA-6000 thermal analyzer, using a heating rate of $5{ }^{\circ} \mathrm{C} /$ min under a synthetic air flow $(20 \mathrm{ml} / \mathrm{min})$.

\subsection{Mechanical strength measurements}

In order to investigate the mechanical properties of the granules, it was performed an axial compression test using the SkyScan 1172 microtomograph. The final cylindrical SBA-15 extrudates had their vertical surfaces previously smoothened by a thin sandpaper, to achieve a more uniform load distribution. The axial crushing stress of the extrudates was determined by the following equation:

$$
\sigma=\frac{4 F}{\pi D^{2}}
$$

where, $F$ is the load applied at the point of breakage and $D$ is the particle diameter.

Each SBA-15 extrudate was placed in the microtomograph equipment and the load was applied along the vertical (axial) direction until it exhibited failure. About 10 cylindrical extrudates with approximately $3 \mathrm{~mm}$ diameter and $4 \mathrm{~mm}$ length were subjected to the crushing strength test from each set of the paste compositions.

\section{Results and Discussion}

\subsection{Absence of binder}

The absence of binder (Methocel A4M) was analyzed by comparing green body and calcined samples of SBA-15 mesoporous silica extrudate samples. Figure 5 shows the thermogravimetry curves obtained for the green body of

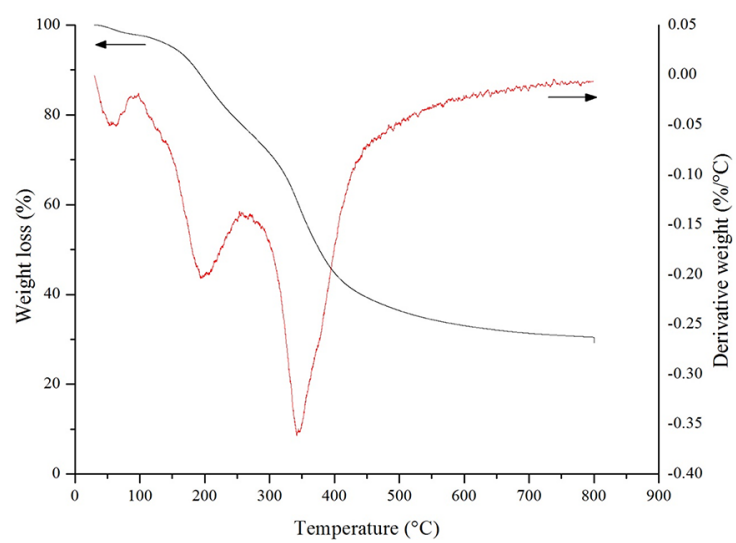

Figure 5. TG and DTG curves of green bodies of SBA-15 silica extrudates. 
SBA-15 mesoporous silica extrudates, carried out from between 30 to $800^{\circ} \mathrm{C}$. The DTG curve shows three distinct stages of weight losses. The first weight loss, occurred around $60{ }^{\circ} \mathrm{C}$, can be attributed to desorption of gases and adsorbed water. The second and third peaks occur between $150{ }^{\circ} \mathrm{C}$ and $400{ }^{\circ} \mathrm{C}$ and correspond to the decomposition of the organics (methocel and Pluronics P123 ${ }^{9,15}$ ). It is important to emphasize that the SBA-15 powders used in this research were not previously calcined, i.e. the P123 surfactant was present in the micro-mesoporous structure during the granulation process. Therefore, all the organic binder was removed when the dried extrudates were subjected to heat treatment above $500{ }^{\circ} \mathrm{C}$. From 600 to $800{ }^{\circ} \mathrm{C}$, the curve presents a steady weight loss, which can be associated to the dehydroxylation of -OH groups, present on the surface of the material ${ }^{9}$.

Figure 6 shows the FTIR spectra of the following samples: SBA-15 silica in powder, SBA-15 silica granule prepared with 20 wt. $\%$ of methocel A4M after heat treatment at 800 ${ }^{\circ} \mathrm{C}$, green body of SBA-15 granule prepared with $20 \mathrm{wt} . \%$ of methocel A4M, and pure methocel A4M. The FTIR spectra of pure methocel A4M shows typical peaks, e.g. at $3449 \mathrm{~cm}^{-1}$ assigned to $\mathrm{O}-\mathrm{H}$ stretching, at $1644 \mathrm{~cm}^{-1}$ related to sugar ring and $1067 \mathrm{~cm}^{-1}$ due to $\mathrm{C}-\mathrm{O}$ (ether) stretching ${ }^{16}$. Concerning the SBA-15 silica samples, the main silicon bands are from
3700 to $3200 \mathrm{~cm}^{-1}$, caused by $\mathrm{O}-\mathrm{H}$ stretching, and from 1300 to $1000 \mathrm{~cm}^{-1}$, due to Si-O-Si asymmetric stretching ${ }^{17}$. Comparing the FTIR spectra of SBA-15 samples, one can observe that the organic peaks present in the methocel spectra are also found in the sample of SBA- 15 containing $20 \%$ of binder, indicating the presence of the binder in the sample. On the other hand, these peaks were not found in the calcined sample, demonstrating the removal of the organic binder.

\subsection{Porosity evaluation}

The influence of the extrusion process and the calcination temperature on the final surface area and porosity was analyzed by comparing the different SBA-15 samples, by $\mathrm{N}_{2}$ sorption. Nitrogen adsorption isotherms of SBA-15 mesoporous silica samples are shown in Figure 7, while the pore size distribution is shown in Figure 8. Finally, the surface area and pore volume are listed on Table 1. One can observe that all isotherms exhibit type IV of IUPAC classification and an H1-type hysteresis loop ${ }^{18}$, characteristic of mesoporous materials. This means that the mesoporous structure was not changed by the granulation process. However, there are important changes that should be pointed out. The main difference observed is the larger volume of nitrogen adsorbed for the SBA-15 silica powder calcined at $550{ }^{\circ} \mathrm{C}$. The surface area decreased almost by half with

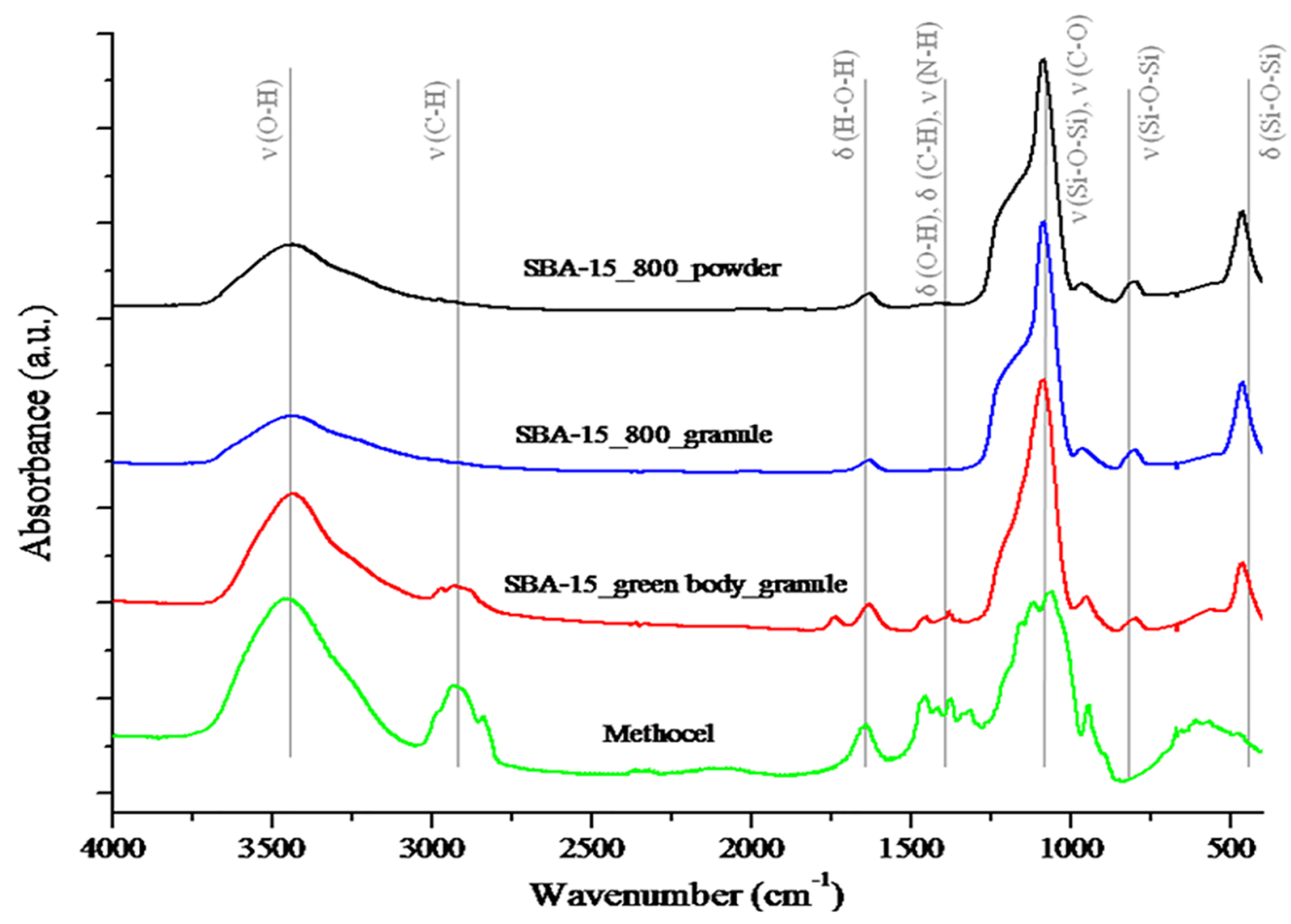

Figure 6. Fourier transform infrared (FTIR) absorption spectra of SBA-15 samples, before and after heat treatment at $800{ }^{\circ} \mathrm{C}$, and methocel used as the organic binder. 


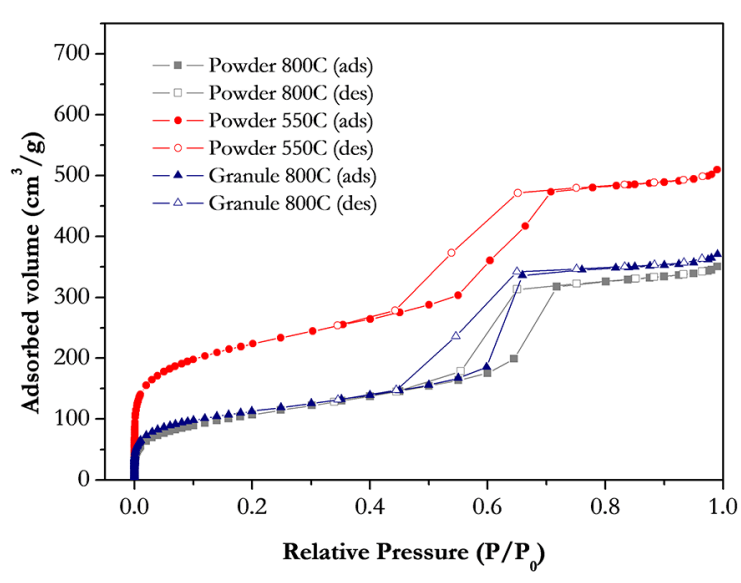

Figure 7. Nitrogen adsorption isotherms of SBA-15 mesoporous silica samples.

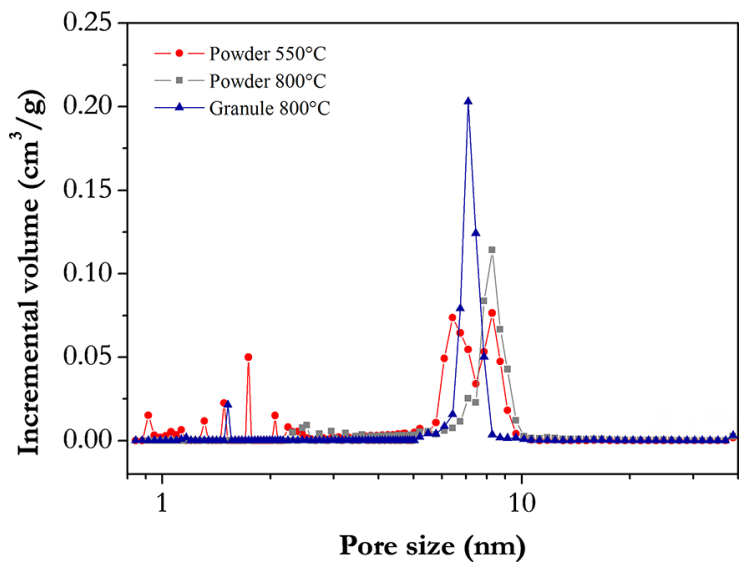

Figure 8. Pore size distribution of SBA-15 silica samples.

Table 1. Results of the surface area and the pore volume for SBA15 samples.

\begin{tabular}{lccc}
\hline SAMPLES & $\mathrm{S}_{\mathrm{A}}\left(\mathrm{m}^{2} / \mathrm{g}\right)$ & $\mathrm{V}_{\text {pores }}\left(\mathrm{cm}^{3} / \mathrm{g}\right)$ & $\mathrm{V}_{\text {micropores }}\left(\mathrm{cm}^{3} / \mathrm{g}\right)$ \\
\hline $\begin{array}{l}\text { SBA-15_- } \\
\text { powder_550 }\end{array}$ & 758 & 0.73 & 0.13 \\
$\begin{array}{l}\text { SBA-15_- } \\
\text { powder_800 }\end{array}$ & 386 & 0.50 & 0.00 \\
$\begin{array}{l}\text { SBA-15_ } \\
\text { granules_800 }\end{array}$ & 392 & 0.53 & 0.02 \\
\hline
\end{tabular}

the increase in the heat treatment temperature, i.e. from 758 $\mathrm{m}^{2} / \mathrm{g}$ (in SBA- 15 powder calcined at $550{ }^{\circ} \mathrm{C}$ ) to $386 \mathrm{~m}^{2} / \mathrm{g}$ (in SBA- 15 powder calcined at $800^{\circ} \mathrm{C}$ ). It is believed that the reduction of the surface area is due to the elimination of some micropores, as shown in the pore size distributions graph. This result confirms that the porosity and surface area are strongly dependet on the calcination temperature, rather than the granulation process ${ }^{19}$.

Regarding the SBA- 15 silica samples calcined at $800{ }^{\circ} \mathrm{C}$, one can notice a slight increase of adsorption volume in the granulated samples at higher relative $\mathrm{N}_{2}$ pressures. The surface area and pore volume of SBA-15 granules calcined at $800{ }^{\circ} \mathrm{C}$ were found to be around $392 \mathrm{~m}^{2} / \mathrm{g}$ and $0.53 \mathrm{~cm}^{3} / \mathrm{g}$, respectively. In addition, SBA-15 extrudates showed a narrow distribution pore size, with pore size of $7 \mathrm{~nm}$.

The surface area obtained for SBA-15 samples prepared in this work showed a higher value when compared to the results of Chandrasekar et al. ${ }^{12}$. In more detail, when the calcination temperature increased from $550^{\circ} \mathrm{C}$ to $750{ }^{\circ} \mathrm{C}$, the surface area of their SBA-15 extrudates decreased from $640 \mathrm{~m}^{2} / \mathrm{g}$ to $400 \mathrm{~m}^{2} / \mathrm{g}$, and exhibited only $261 \mathrm{~m}^{2} / \mathrm{g}$ when the temperature was above $750{ }^{\circ} \mathrm{C}$. Chandrasekar's SBA15 extrudates were prepared with $2.2 \mathrm{wt} \%$ of bentonite and $2.2 \mathrm{wt} \%$ of methylcellulose, while the samples in this work are clay-free.

\subsection{Mechanical strength}

The axial crushing strength of the extrudates produced in this work was also evaluated. The extrudates calcined at $800{ }^{\circ} \mathrm{C}$ showed $8.3 \pm 2.7 \mathrm{MPa}$ of axial crushing stress. This value was also higher when compared to the results of Chandrasekar et al. ${ }^{12}$. Using bentonite (inorganic binder) and methycellulose (organic binder and plasticizer), they obtained values varying from 0.4 to $3.4 \mathrm{MPa}$. The increase of the mechanical strength is related to the formation of stronger chemical bonds at a higher temperature $\left(800^{\circ} \mathrm{C}\right)$. Therefore, more energy is necessary to break them. This is an important result, since the clay-free silica granules produced in this work have similar or better mechanical performance compared to the literature.

\section{Conclusions}

The main outcome of this research is the successful production of clay-free granules of SBA-15 mesoporous silica, in size of millimetres ( 3 to $4 \mathrm{~mm}$ ). This was achieved by extrusion procedure, using methocel $\mathrm{A} 4 \mathrm{M}$ as the organic binder, and calcination temperature of $800^{\circ} \mathrm{C}$. The addition of water was the critical step in the extrusion process.

The axial crushing stress of SBA- 15 extrudates calcined at $800{ }^{\circ} \mathrm{C}$ was $8.3 \pm 2.7 \mathrm{MPa}$. Regarding the calcination temperature, granules and powder of SBA-15 mesoporous silica samples calcined at $800^{\circ} \mathrm{C}$ had a significant decrease in surface area and pore volume, due to shrinkage of the mesoporous structure at higher temperature. Finally, the granules produced in this work have high potential to be used as adsorbents and desiccants. Also this work contributes to clay-free granulation process, producing pure granules of nanomaterials.

\section{Acknowledgments}

The authors thank the financial support of CAPES and FAPEMIG. 


\section{References}

1. Kurdyukov DA, Eurov DA, Kirilenko DA, Kukushkina JA, Sokolov VV, Yagovkina MA, et al. High-surface area spherical micro-mesoporous silica particles. Microporous and Mesoporous Materials. 2016;223:225-229.

2. Zhao D, Wan Y, Zhou W. Mesoporous Nonsilica Materials. In: Zhao D, Wan Y, Zhou W. Ordered Mesoporous Materials. Weinheim: Wiley-VCH Verlag; 2013. p. 293-428.

3. Xing BL, Guo H, Chen LJ, Chen ZF, Zhang CX, Huang GX, et al. Lignite-derived high surface area mesoporous activated carbons for electrochemical capacitors. Fuel Processing Technology. 2015; 138:734-742.

4. Beck JS, Vartuli JC, Roth WJ, Leonowicz ME, Kresge CT, Schmitt KD, et al. A new family of mesoporous molecular sieves prepared with liquid crystal templates. Journal of the American Chemical Society. 1992;114(27):10834-10843.

5. Rahmat N, Abdullah AZ, Mohamed AR. A review: Mesoporous Santa Barbara amorphous-15, types, synthesis and its applications towards biorefinery production. American Journal of Applied Sciences. 2010;7(12):1579-1586.

6. Thielemann JP, Girgsdies F, Schlögl R, Hess C. Pore structure and surface area of silica SBA-15: influence of washing and scale-up. Beilstein Journal of Nanotechnology. 2011;2:110-118.

7. Giraldo L, Moreno-Piraján JC. Study on the adsorption of heavy metal ions from aqueous solution on modified SBA-15. Materials Research. 2013;16(4):745-754.

8. Zhao D, Feng J, Huo Q, Melosh N, Fredrickson GH, Chmelka $\mathrm{BF}$, et al. Triblock copolymer syntheses of mesoporous silica with periodic 50 to 300 angstrom pores. Science. 1998;279(5350):548552.

9. , Kleitz F, Schmidt W, Schüth F. Calcination behavior of different surfactant-templated mesostructured silica materials. Microporous and Mesoporous Materials. 2003;65(1):1-29.
10. Hartmann M, VinuA. Mechanical Stability and Porosity Analysis of Large-Pore SBA-15 Mesoporous Molecular Sieves by Mercury Porosimetry and Organics Adsorption. Langmuir. 2002;18:80108016.

11. Yu C, Fan J, Tian B, Zhao D. Morphology Development of Mesoporous Materials: a Colloidal Phase Separation Mechanism. Chemistry of Materials. 2004;16(5):889-898.

12. Chandrasekar G, Hartmann M, Murugesan V. Preparation of SBA15 extrudates: Evaluation of textural and mechanical properties. Journal of Porous Materials. 2009;16(2):175-183.

13. Vervaet C, Baert L, Remon JP. Extrusion-spheronisation A literature review. International Journal of Pharmaceutics. 1995;116(2):131146.

14. Wilson DI, Rough SL. Extrusion-Spheronisation. In: Salman AD, Hounslow MJ, Seville JPK, eds. Handbook of Powder Technology. Amsterdam: Elsevier; 2007. p. 189-217.

15. Almeida D, Costa L, Vasconcellos L, Dias F. Estudo da remoção do surfactante Pluronic 123 (P123) de organosílicas mesoporosas periódicas (PMOs) por solvente em diferentes condições. In: 32a Reunião Anual da Sociedade Brasileira de Química; 2009 May 30 - Jun 2; Fortaleza, CE, Brazil.

16. Patil SA, Kuchekar BS, Chabukswar AR, Jagdale SC. Formulation and Evaluation of Extended-Release Solid Dispersion of Metformin Hydrochloride. Journal of Young Pharmacists. 2010;2(2):121-129.

17. Stuart B. Infrared Spectroscopy: Fundamentals and Applications. Hoboken: John Wiley \& Sons; 2004.

18. Sing KSW, Everett DH, Haul RAW, Moscou L, Pierotti RA, Rouquérol J, et al. Reporting Physisorption data for Gas/Solid Systems with Special Reference to the Determination of Surface Area and Porosity (Recommendations 1984). Pure \& Applied Chemistry. 1985;57(4):603-619.

19. Yang PD, Zhao DY, Margolese DI, Chmelka BF, Stucky GD. Generalized syntheses of large-pore mesoporous metal oxides with semicrystalline frameworks. Nature. 1998;396:152-155. 